\title{
Study on Efficiency of Protein Extractants Employed for Human Origin Determination of Blood
}

\section{Usha Rani M*, Vijayendran P, and Thangadurai M}

Biology division, Regional Forensic Science Laboratory, Madurai - 625020, Tamilnadu, India

${ }^{*}$ Corresponding author: Usha Rani M, Regional Forensic Science Laboratory, Madurai-625020, Tamilnadu, India, Tel: 0452-2531966, E-mail: rfslmadurai@gmail.com

Citation: Usha Rani M, Vijayendran P, Thangadurai M (2014) Study on Efficiency of Protein Extractants Employed for Human Origin Determination of Blood. J Forensic Sci Criminol 2(3): 302. doi: 10.15744/23489804.1.601

Received Date: March 25, 2014 Accepted Date: April 09, 2014 Published Date: June 16, 2014

\begin{abstract}
Human origin determination is an important aspect of blood grouping analysis in forensic science laboratories. In the present study, protein extractants like gel buffer, ammonia and saline employed for origin determination were evaluated and compared qualitatively and quantitatively for their role in the extraction of proteins from dried blood stained materials of human origin at regular time intervals. Qualitative and quantitative methods employing counter immunoelectrophoresis (CIE) and rocket immunoelectrophoresis (RIE) respectively were used to study the protein extraction efficiency of extractants. Ammonia, compared to gel buffer and saline extracted the proteins effectively. Maximum extraction of proteins was observed in 2-3 hours of sample. CIE demonstrated sharp precipitin bands with all samples of ammonia extractant compared to the samples of counterparts. RIE also revealed greater concentration of proteins in the ammonia extract compared to extracts of gel buffer and saline. These results provide evidence that ammonia serves as a better protein extractant for rapid determination of human blood origin.
\end{abstract}

Keywords: Forensic science; Forensic serology; Blood origin; Electrophoresis; Protein extractants; Immunoprecipitation

\section{Introduction}

Origin determination of humans is an important aspect of blood grouping analysis in forensic science laboratories. Once a biological material is evidenced to be blood, it is necessary to determine whether the blood is of human or non-human origin [1]. Generally, origin determination is done by making use of antigen-antibody reaction where species specific proteins present in the blood stains is identified with the help of species specific antibodies.

Counter immunoelectrophoresis (CIE) is a kind of immunoprecipitation technique commonly and qualitatively employed for origin determination of blood. This technique exploits the principle that antigens and antibodies migrate towards each other during electrophoresis and form a precipitin arc at the antigen-antibody equivalence point [2]. Therefore this method of immunodiffusion in the presence of electrical field indicates the presence of antigens (proteins) in the sample during the formation of precipitin line. Rocket immunoelectrophoresis (RIE) is a technique of quantitating antigen where electrical force is used to facilitate antigen migration in gel containing specific antibodies. During this process, migrating antigen meets the corresponding antibodies and forms a rocket-like precipitin peak; the peak height varies proportional to the antigen concentration.

Proteins (antigens) of dried blood stains are extracted using protein extractants and allowed to migrate against specific antibodies for origin determination. Protein extractants that are commonly used by forensic laboratories during origin determination include gel buffer (barbital buffer $\mathrm{pH}$ 8.6), 5\% ammonia and physiological saline (0.89\%). Each extractants have their unique properties and differ in the efficiency of extraction of proteins. Hence it is necessary to choose a better extractant with better extraction efficiency of proteins from different types of blood stained materials during human origin determination of blood.

In the present study, protein extractants like gel buffer, $5 \%$ ammonia and saline solution were evaluated and compared for their extraction efficiency of proteins from dried blood stained materials of human origin using counter immunoelectrophoresis on time scale basis. Rocket immunoelectrophoresis was also employed to quantitate the amount of protein extracted and thereby to ascertain the efficacy of protein extractants.

\section{Materials and Methods}

\section{Chemicals}

Chemicals and reagents like ammonia, sodium barbiturate, diethyl barbituric acid, calcium lactate, sodium chloride, coomassie brilliant blue, bromophenol blue, methanol, glacial acetic acid and agar powder used in the current study were of analytical grade. Antihuman serum globulin (antiserum raised in rabbit) was obtained from Institute of Serology, Kolkatta, India. 


\section{Protein extractants}

Protein extractants namely gel buffer (barbital buffer, $\mathrm{pH}$ 8.6), 5\% ammonia and physiological saline were included in the current study to evaluate and compare their protein extraction efficiency. Gel buffer was prepared by dissolving 7 gm of sodium barbiturate, $1.1 \mathrm{gm}$ of diethyl barbituric acid and $1 \mathrm{gm}$ of calcium lactate in 1 litre of distilled water. $5 \%$ ammonia solution was prepared by diluting $5 \mathrm{ml}$ of concentrated ammonia with $95 \mathrm{ml}$ distilled water. Physiological saline (0.89\%) was made by dissolving $890 \mathrm{mg}$ of sodium chloride in $100 \mathrm{ml}$ of distilled water.

\section{Sample material and extract preparation}

The unexpended portions of one month aged dried blood stained materials received in the biology division of Regional Forensic Science Laboratory, Madurai were used for the present study. Six different items of dried blood stained materials of human origin (Item 1 - Shirt, Item 2 - Saree, Item 3 - Pant, Item 4 - Control blood, Item 5 - Lungi, Item 6 - SNS [stain not superimposable knife swab]; Items 1 and 2 - synthetic, Items 3-6 - cotton) were selected; the region containing homogenous blood stains were cut into small pieces and mixed well. Each item was distributed equally (30 mg) in three eppendorf tubes. About $300 \mu \mathrm{L}$ of protein extractants - gel buffer, 5\% ammonia and saline were added to three respective eppendorf tubes of each item. At half an hour intervals for a period of three hours, the incubated samples were mixed well, centrifuged and $40 \mu \mathrm{L}$ supernatant was collected and used for the study.

\section{Counter immunoelectrophoresis}

Counter immunoelectrophoresis was performed according to the procedure described by Bunsal et al [3] with slight modifications. $1.25 \mathrm{~g}$ agar was dissolved in $100 \mathrm{ml}$ (1.25\%) of tank buffer (barbital buffer ( $\mathrm{pH}$ 8.6)- prepared by dissolving 8.76 gm of sodium barbiturate, $1.38 \mathrm{gm}$ diethyl barbituric acid and $0.38 \mathrm{gm}$ of calcium lactate in 1 litre distilled water) in a boiling water bath till the solution became clear. The molten agar solution was then immediately poured onto the glass plate, allowing the gel to solidify. Wells for applying samples (stain extracts) and antiserum respectively were punched on the solidified gel using a gel puncher. 10 $\mu \mathrm{L}$ of stain extracts of each item obtained using different protein extractants at different time intervals were applied to each well that are situated closer to the cathode. $10 \mu \mathrm{L}$ of antihuman serum globulin was applied to the wells that were closer to the anode. Electrophoresis was performed using tank buffer at $100 \mathrm{~V}$ for $45 \mathrm{~min}$. The developed plate was incubated overnight in saline at room temperature. Next day, the saline was removed and was incubated in distilled water for $1 \mathrm{hr}$. The plate was then covered with damp filter paper and kept in oven till the filter paper became dry. The plate was washed with water and incubated in coomassie brilliant blue (CBB) dye for $30 \mathrm{~min}$. The gel plate was destained till excess stain was removed and a blue precipitin band was seen in a clear background.

\section{Rocket immunoelectrophoresis}

Rocket immunoelectrophoresis was performed according to the method of Laurell [4]. 1.25\% agar gel was prepared in tank buffer by heating. The molten agarose solution was cooled to $55{ }^{\circ} \mathrm{C}$ and $3 \%$ antihuman antibody was added and swirled gently. The gel mixture was then immediately poured onto the glass plate, allowing the gel to solidify. Wells were punched on the solidified gel using a gel puncher. $10 \mu \mathrm{L}$ of stain extracts of each item obtained using different protein extractants at different time intervals and $5 \mu \mathrm{L}$ of $0.02 \%$ bromophenol blue marker were applied to each well. Electrophoresis was performed using tank buffer at 150 V. The electrophoretic run was continued till the marker dye reached the other end. The gel plate was then stained for proteins as described previously and was observed for precipitin peaks in the shape of rocket formed against a dark background. The tip of the precipitin peak was marked and the peak height was measured from the upper edge of the well to the tip of the peak. A graph was drawn with different stain extracts of each item at different time intervals along X-axis and peak height along Y-axis for the determination of efficiency of protein extractants quantitatively.

\section{Statistical analysis}

Data were presented as mean \pm SD. Two-way ANOVA was used to compare the effects of stain extractants and time (as independent variables) on extraction efficiency of proteins in rocket immunoelectrophoresis. Assumptions of the ANOVA, normality and equal variance were met and statistical significance was set at $p<0.05$.

\section{Results and Discussion}

The present study evaluates and compares the protein extraction efficiency of the extractants namely gel buffer, ammonia and saline that are commonly employed for human origin determination of blood. Qualitative and quantitative methods employing counter immunoelectrophoresis and rocket immunoelectrophoresis revealed better protein extraction efficiency for ammonia extractant in 2-3 hours of sample compared to gel buffer and saline extractants. 
Counter immunoelectrophoresis is a double diffusion technique where antigen and antibody diffuse towards each other under electric field in a gel and form a precipitin line at the point of equivalence. In the present study, the stain extracts obtained using different protein extractants and at different time intervals were subjected to CIE and the gel plate was observed after staining for proteins with $\mathrm{CBB}$ dye (Figure 1). Initially, the pattern of precipitin lines formed between stain extracts and antiserum revealed their optimum concentration that were employed for the precipitation reactions in the present study. The results of the study demonstrated sharp precipitin lines for all the stain extracts prepared using ammonia extractant. In contrast, gel buffer and saline extracts did not reveal sharp precipitin lines for certain items. For instance, the gel buffer and saline extracts of item 4 collected at

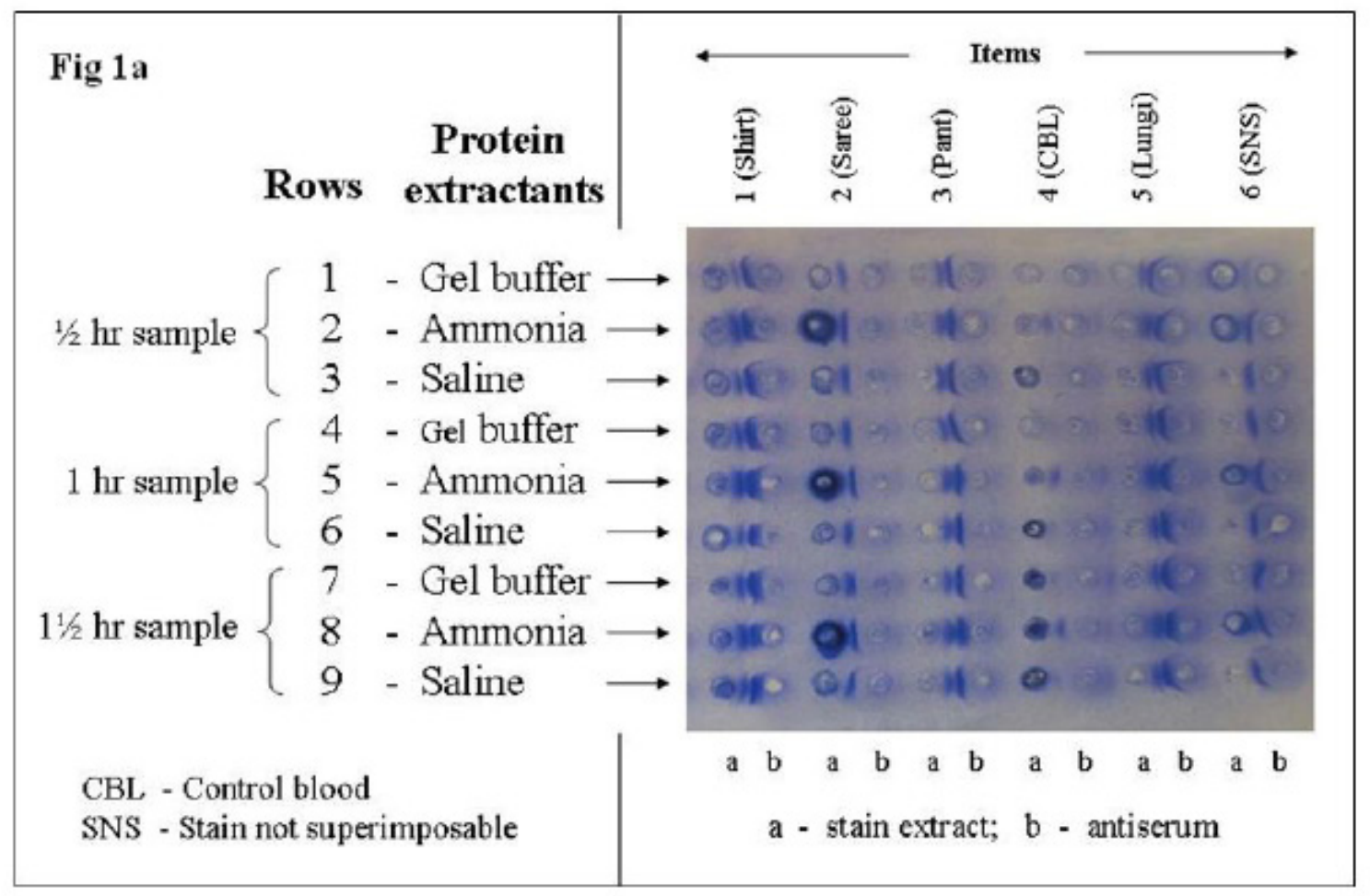

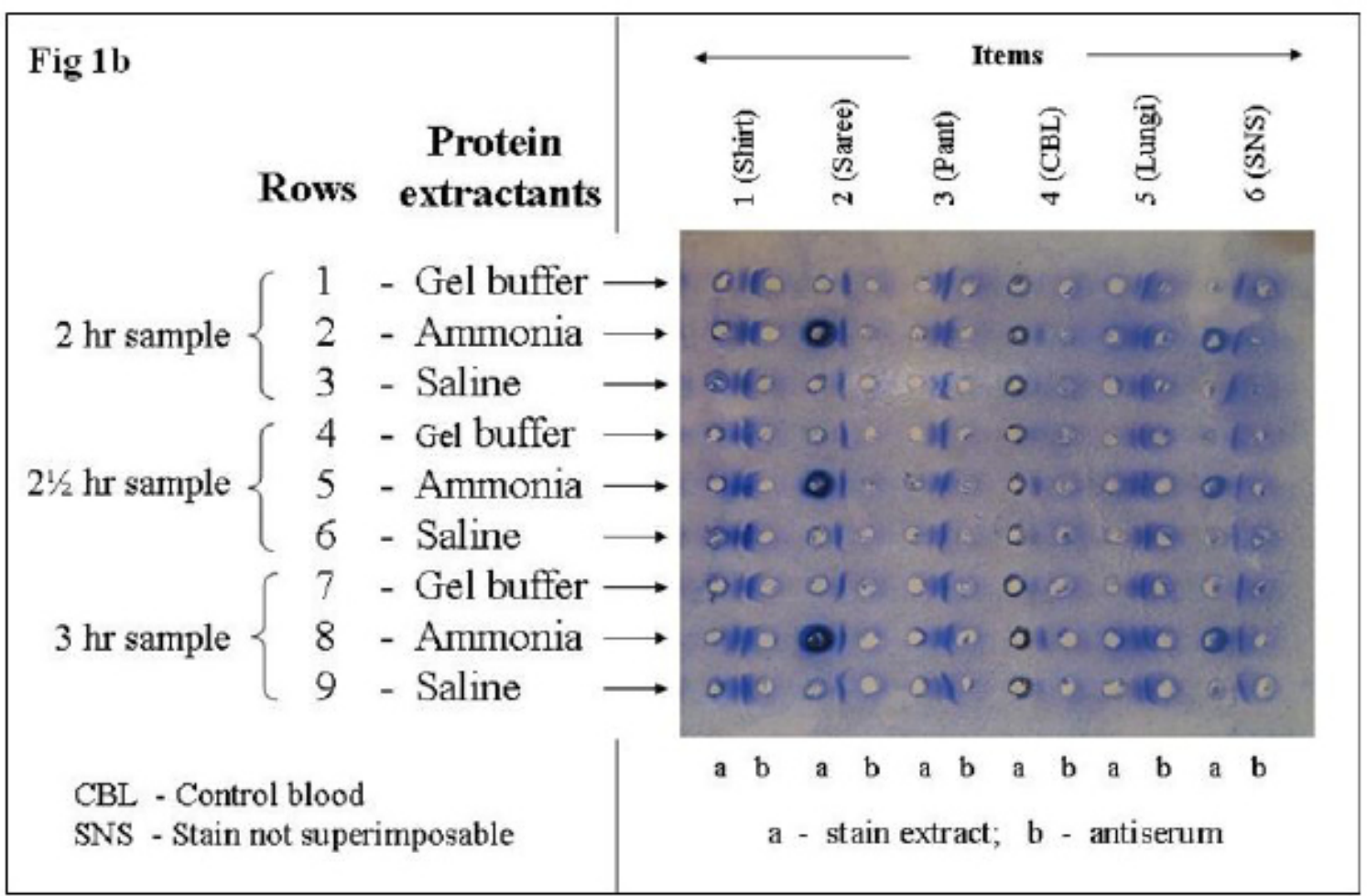

Figure 1: Counter immunoelectrophoresis assay for stain extracts (items 1-6) obtained using different protein extractants and at different time intervals ( Figure 1a : $1 / 2 \mathrm{hr}-1 \frac{1}{2} \mathrm{hr}$ samples; Figure $1 \mathrm{~b}-2 \mathrm{hr}-3 \mathrm{hr}$ samples). The precipitin lines have been observed as a blue band in a clear background after staining for proteins with CBB dye. 
various intervals of time did not reveal any precipitin lines. However, the stain extract of the item 4 prepared using ammonia extractant demonstrated the presence of precipitin lines at all the time intervals (Figure 1). This indicates the ability of ammonia solution to extract the protein from stained material of diverse types compared to gel buffer and saline extractants. Also, the intensity of the precipitin line was greater for stain extracts of ammonia in comparison with the respective time interval samples of the gel buffer and saline stain extracts, indicating the protein extraction efficiency of ammonia extractant. Consistent with these study results, it has been reported that $5 \%$ ammonia solution is a better extractant for aged stains and stains on synthetic fibres [1]. It has also been suggested that ammoniacal elution is much useful during typing of bloodstains [1]. Balas et al [5] have also demonstrated optimum extraction of proteins from switchgrass using aqueous ammonia with an integrated biorefinery. The technique of antigen-antibody reaction in CIE takes place rapidly under the influence of two different forces: antigen migrates towards anode by electrical current and antibody moves in the opposite direction (i.e.) towards cathode by electroendosmosis. Antigen meets antibodies and an immunoprecipitate is formed at the equivalence point [6]. This method of electrophoresis therefore yields a qualitative result of extraction efficiency of protein extractants in the current study.

Rocket immunoelectrophoresis, is a simple, rapid, reproducible, and novel technique of electroimmunodiffusion described by Laurel [4]. This method is commonly used for quantitative purposes and is based on selective migration of antigens by electrical force through an antibody containing gel [2]. Antigen initially forms soluble antigen-antibody complexes during its migration; then precipitation networks builds up along the edges of the migrating antigen zone starting from the bottom. Finally, a 'rocketlike' precipitation is resulted in accordance with the antigen concentration. In the current study, the stain extracts of study items prepared using protein extractants at different time intervals were subjected to rocket electrophoresis to quantify the amount of protein extracted by the extractants. The results indicated the development of rocket like precipitin peaks for most of the stain extracts of study items in proportion with the concentration of protein (antigen) extracted by the protein extractants (Figure 2).

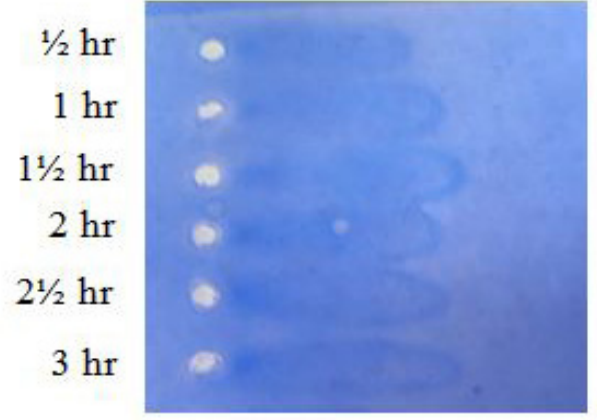

Gel buffer

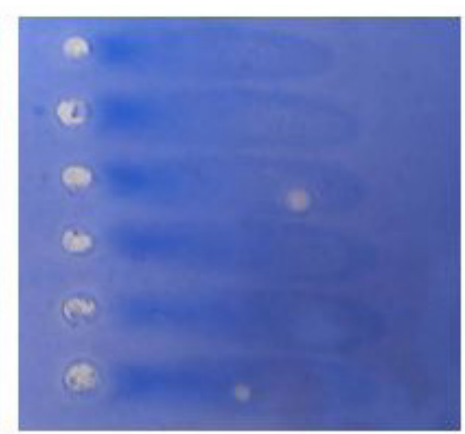

Ammonia

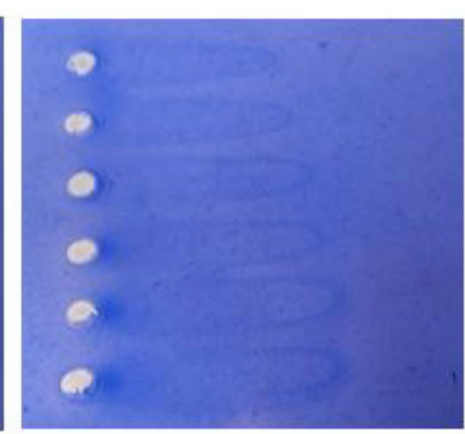

Saline

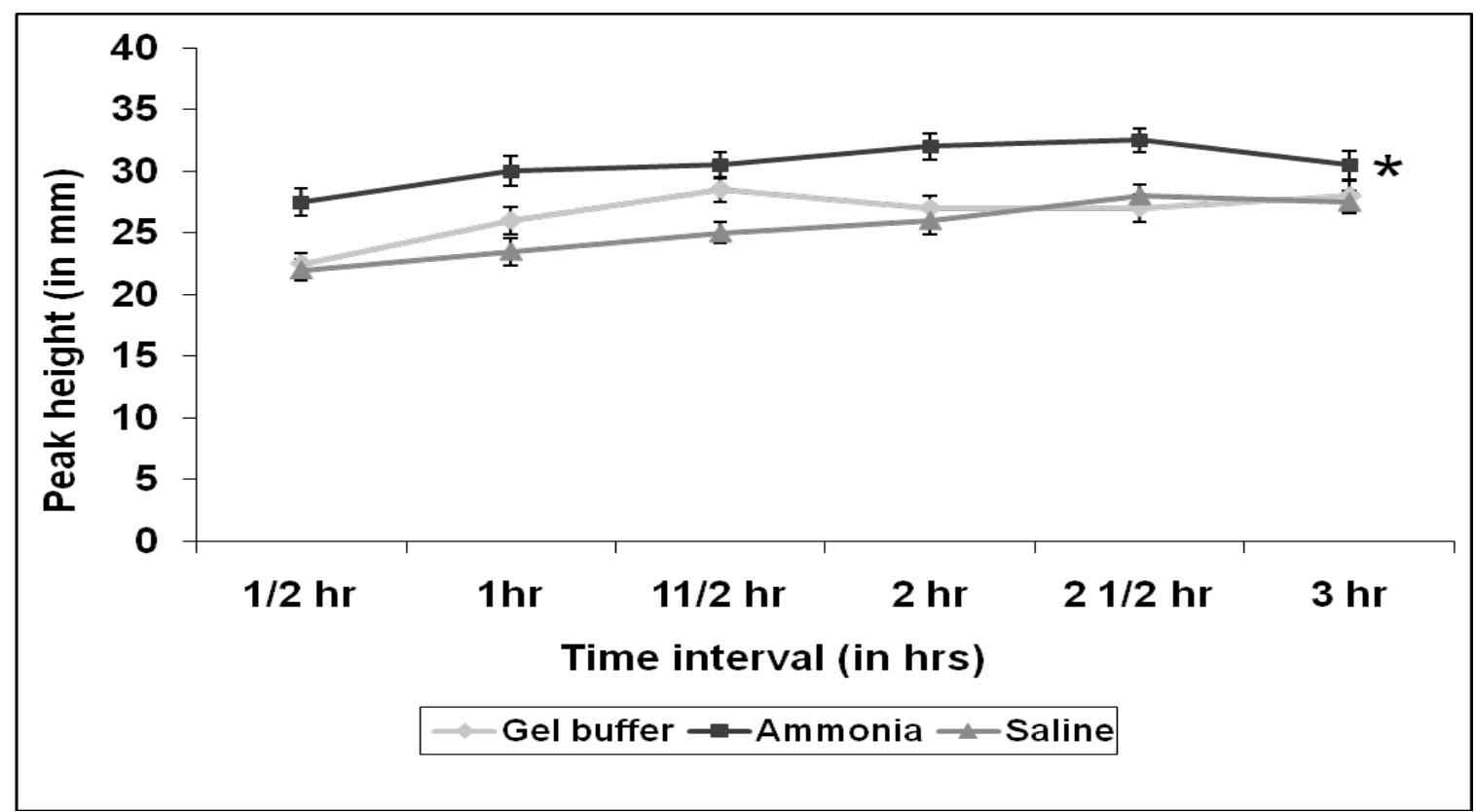

Figure 2: Rocket immunoelectrophoresis of stain extracts (items 1-6) obtained using different protein extractants and at different time intervals. The precipitin peaks were observed in the shape of rocket formed against a dark background after staining for proteins with CBB dye.

Figure 2a: Immunogram showing rocket- like precipitin peaks and a line graph demonstrating the extraction efficiency of protein extractants at different time intervals for item 1 . Results of line graph are means \pm SD $(n=3)$. Two-way ANOVA showed significant effect of stain extractants and time on extraction efficiency of proteins in rocket immunoelectrophoresis $\left({ }^{*} \mathrm{p}<0.05 ; 2\right.$-way ANOVA) 
The development and height of the precipitin peaks were in accordance with the presence and intensity of the precipitin lines demonstrated during CIE. Also, the nondevelopment of peaks for gel buffer and saline stain extracts of item 4 were in consistence with the absence of precipitin lines demonstrated during CIE.

A comparative study on the formation of rockets revealed a greater height of precipitin peak being developed for stain extracts of items prepared using ammonia extractant compared to counterparts obtained using gel buffer and saline extractants (Figure 2 ). As the height of the peak is proportional to the concentration of antigen [2], the study results further interpreted that the concentration of protein extracted by the ammonia extractant from the stained materials is significantly $(p<0.05)$ greater than the other extractants, revealing the better extraction efficiency of ammonia extractant. A graph plotted with stain extracts at different time intervals vs. height of the rocket (in $\mathrm{mm}$ ) (Figure 2) demonstrated significantly $(\mathrm{p}<0.05)$ greater peak heights for the stain extracts of ammonia in 2-3 hours of sample in comparison with the respective peak heights observed with gel buffer and saline extractants.

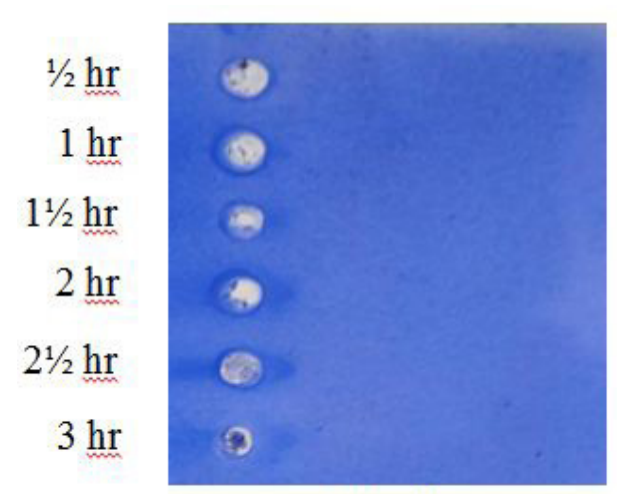

Gel buffer

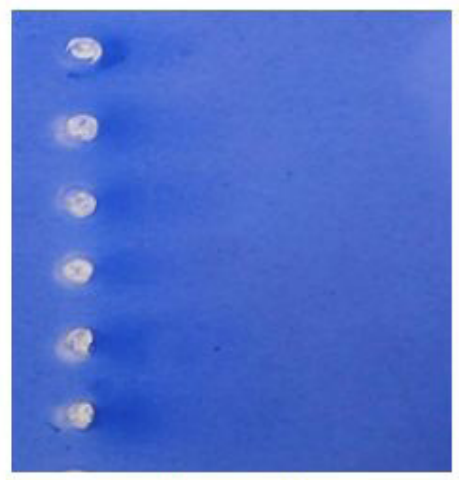

Ammonia

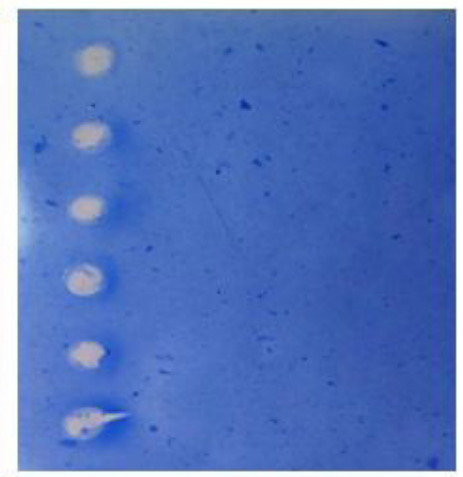

Saline

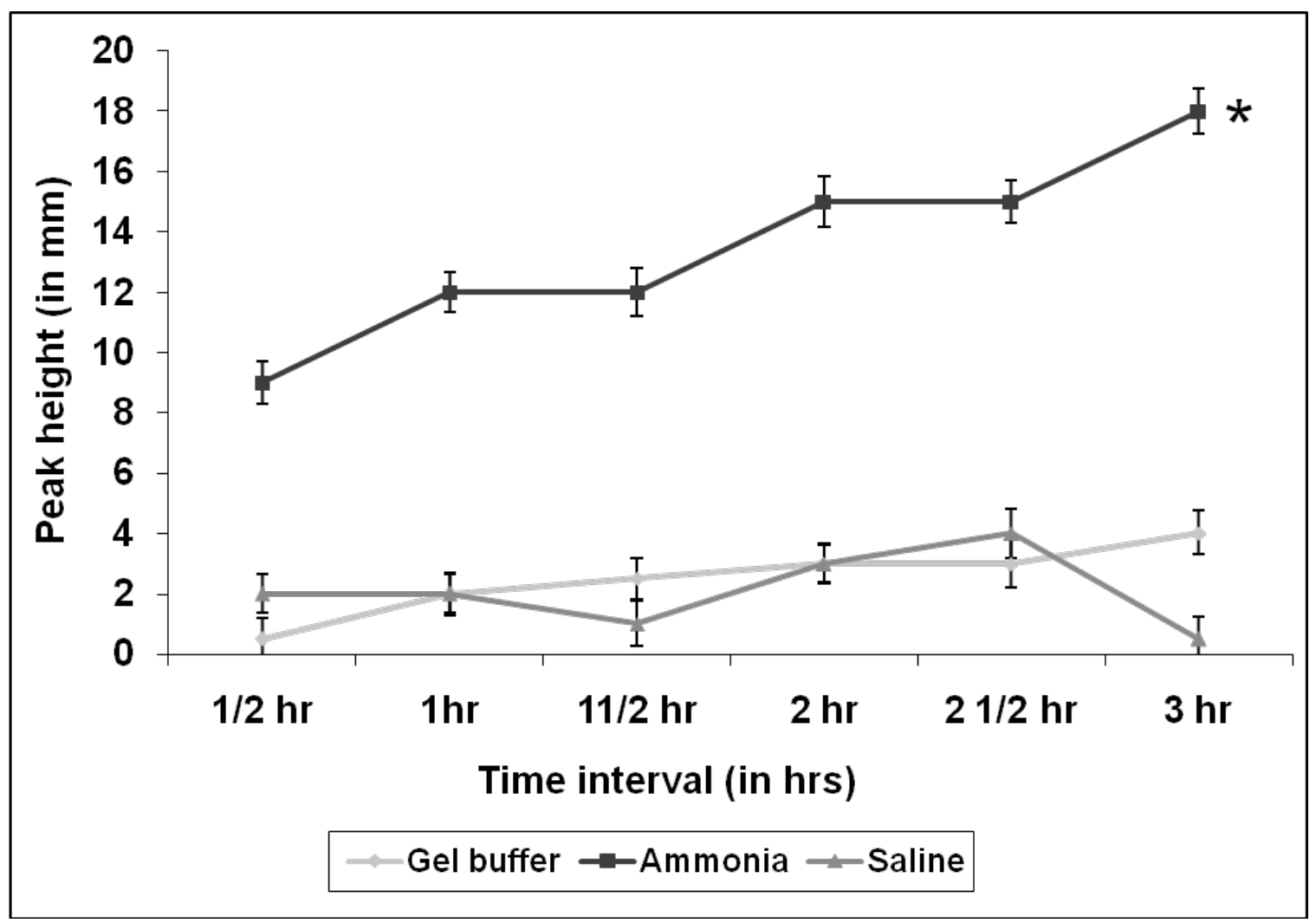

Figure 2b: Immunogram showing rocket- like precipitin peaks and a line graph demonstrating the extraction efficiency of protein extractants at different time intervals for item 2. Results of line graph are means \pm SD $(n=3)$. Two-way ANOVA showed significant effect of stain extractants and time on extraction efficiency of proteins in rocket immunoelectrophoresis $\left({ }^{*} \mathrm{p}<0.05 ; 2\right.$-way ANOVA) 


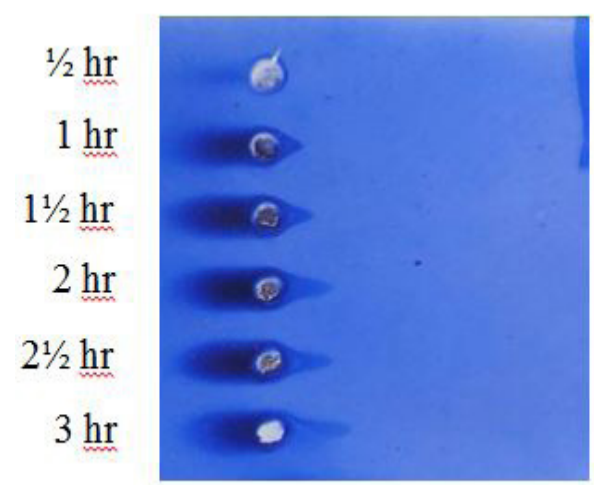

Gel buffer

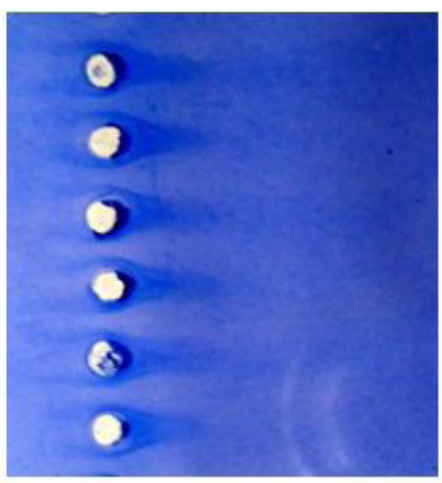

Ammonia

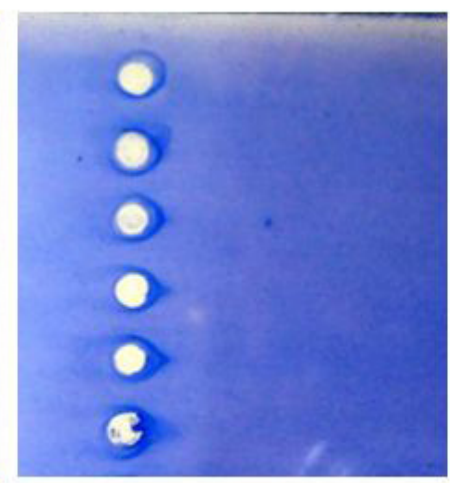

Saline

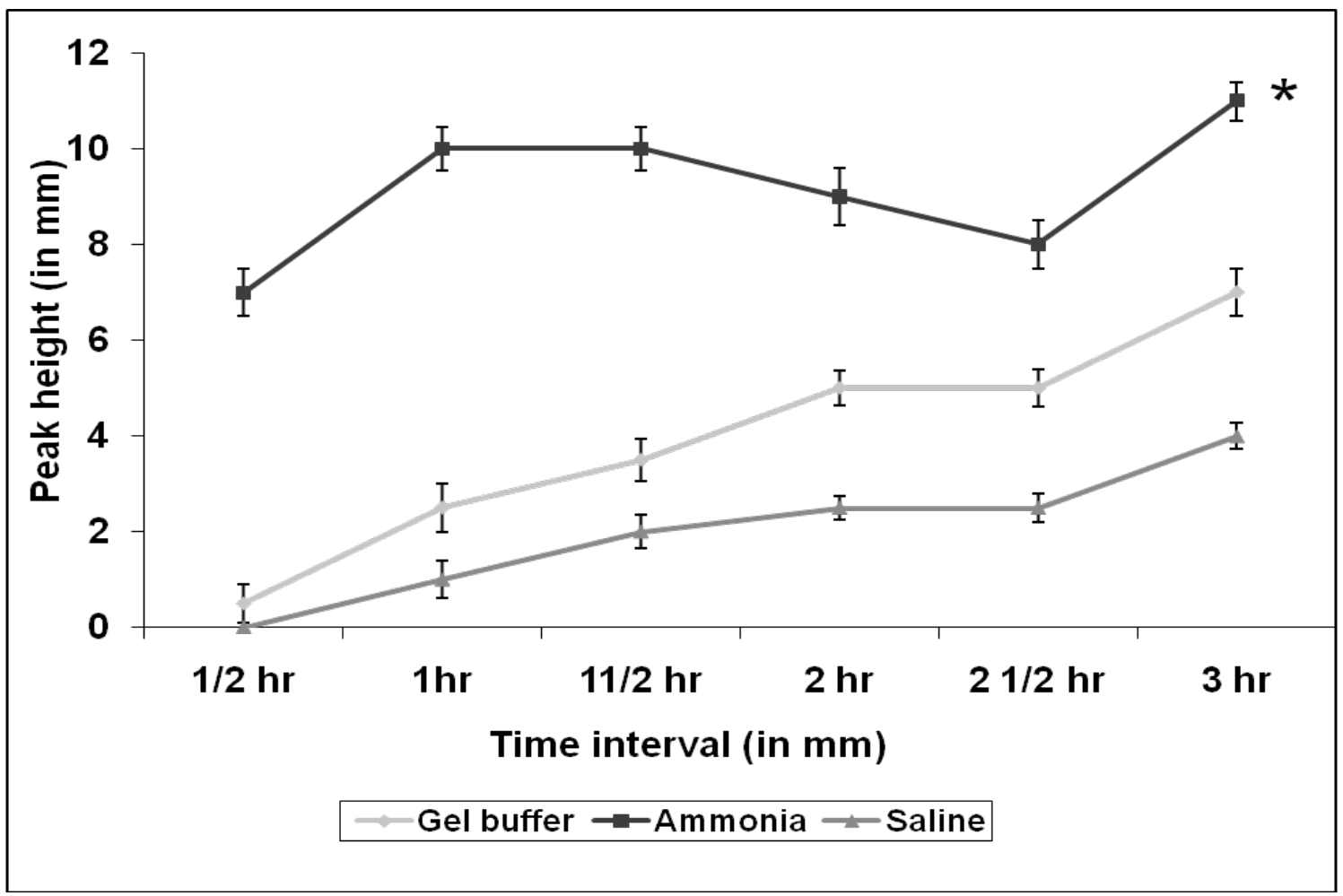

Figure 2c: Immunogram showing rocket- like precipitin peaks and a line graph demonstrating the extraction efficiency of protein extractants at different time intervals for item 3. Results of line graph are means \pm SD $(n=3)$. Two-way ANOVA showed significant effect of stain extractants and time on extraction efficiency of proteins in rocket immunoelectrophoresis $\left({ }^{*} \mathrm{p}<0.05 ; 2\right.$-way ANOVA)

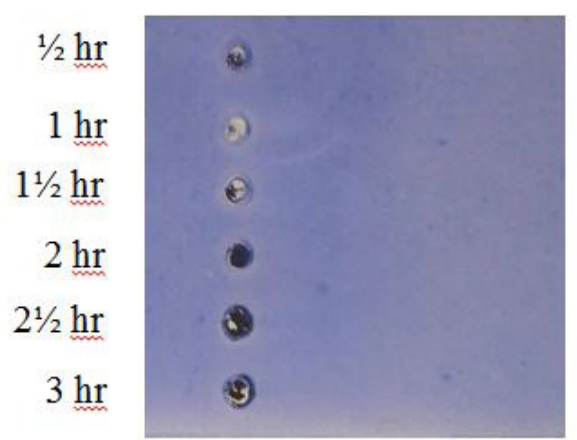

Gel buffer

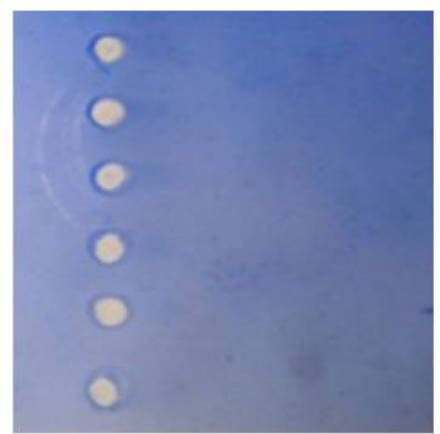

Ammonia

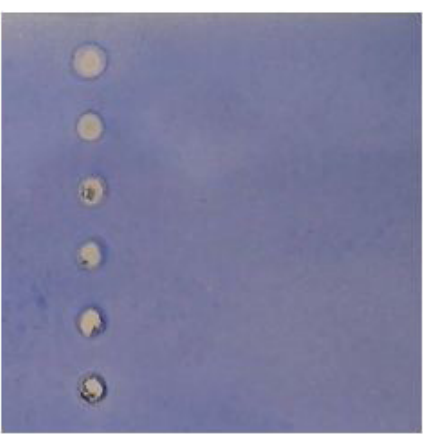

Saline 


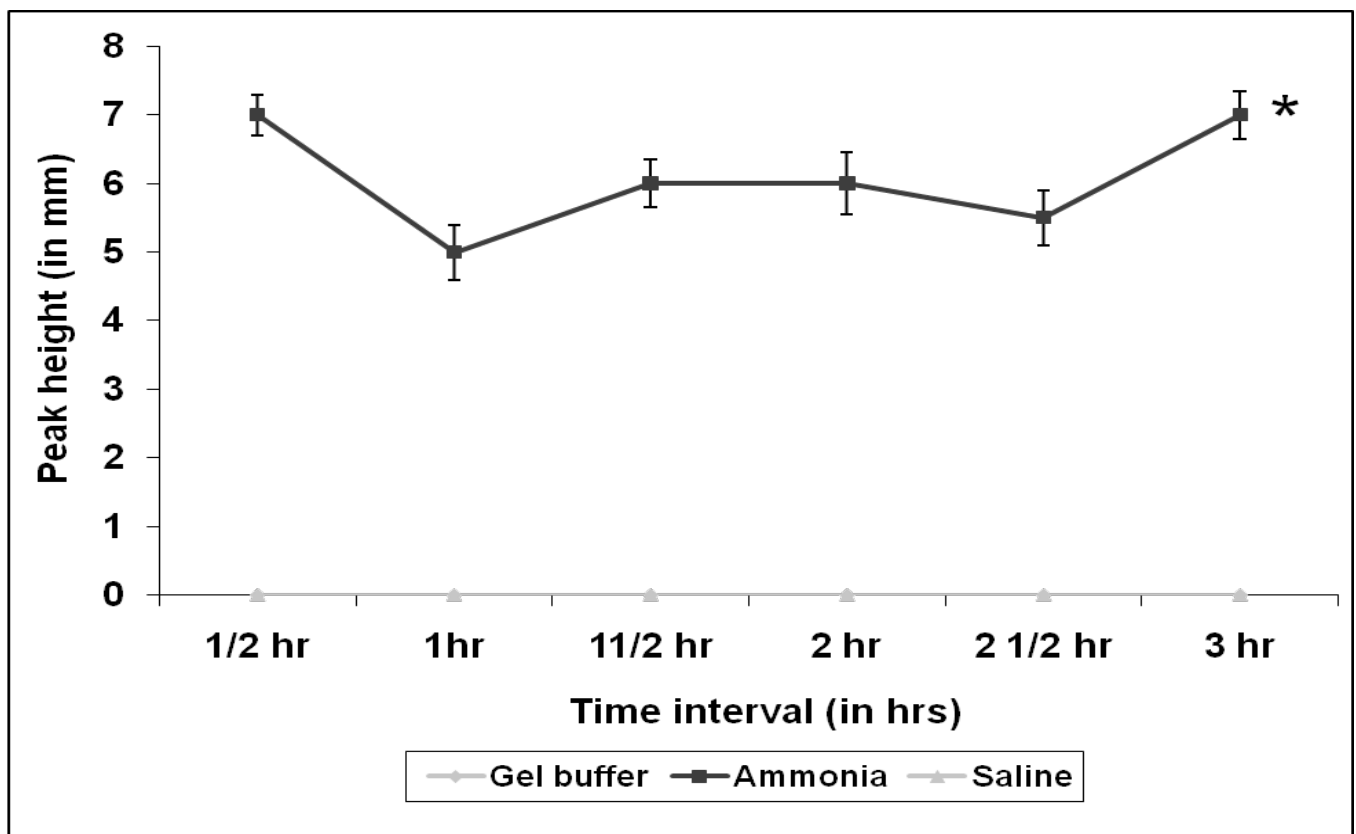

Figure 2d: Immunogram showing rocket- like precipitin peaks and a line graph demonstrating the extraction efficiency of protein extractants at different time intervals for item 4. Results of line graph are means $\pm \mathrm{SD}(\mathrm{n}=3)$. Two-way ANOVA showed significant effect of stain extractants and time on extraction efficiency of proteins in rocket immunoelectrophoresis $\left({ }^{*} \mathrm{p}<0.05 ; 2\right.$-way ANOVA)

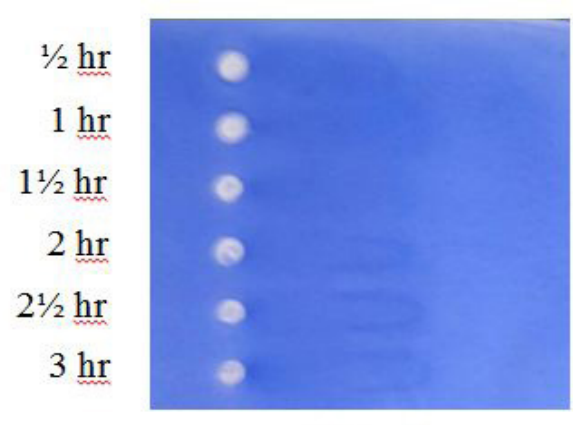

Gel buffer

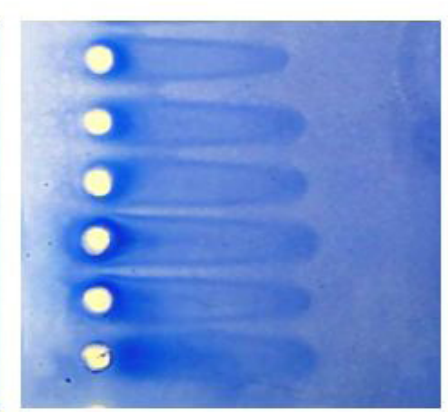

Ammonia

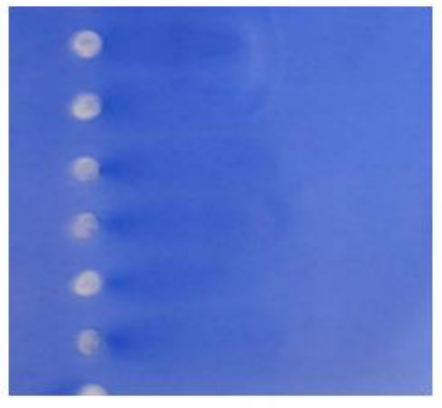

Saline

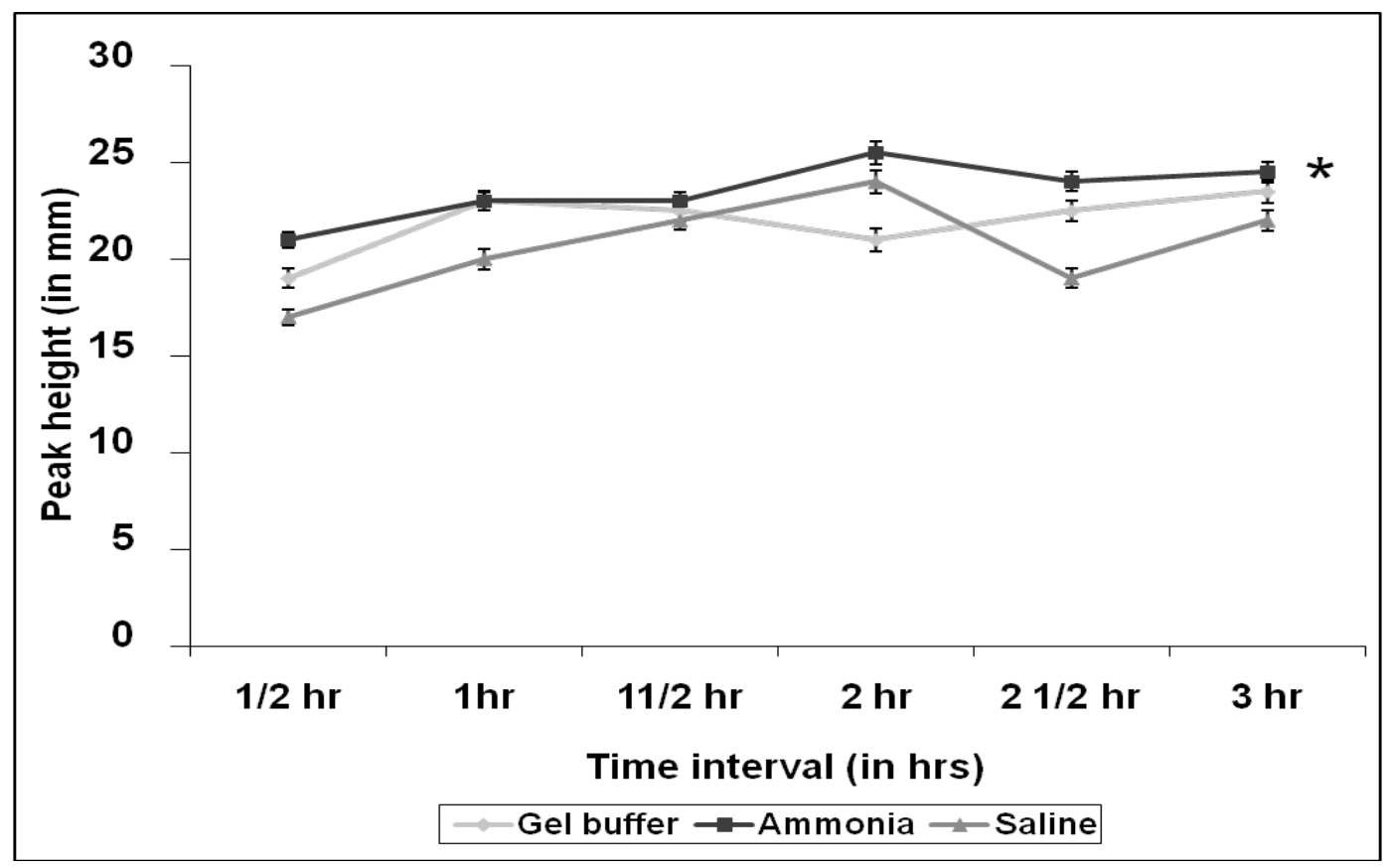

Figure 2e: Immunogram showing rocket- like precipitin peaks and a line graph demonstrating the extraction efficiency of protein extractants at different time intervals for item 5 . Results of line graph are means \pm SD $(n=3)$. Two-way ANOVA showed significant effect of stain extractants and time on extraction efficiency of proteins in rocket immunoelectrophoresis $\left({ }^{*} \mathrm{p}<0.05 ; 2\right.$-way ANOVA) 


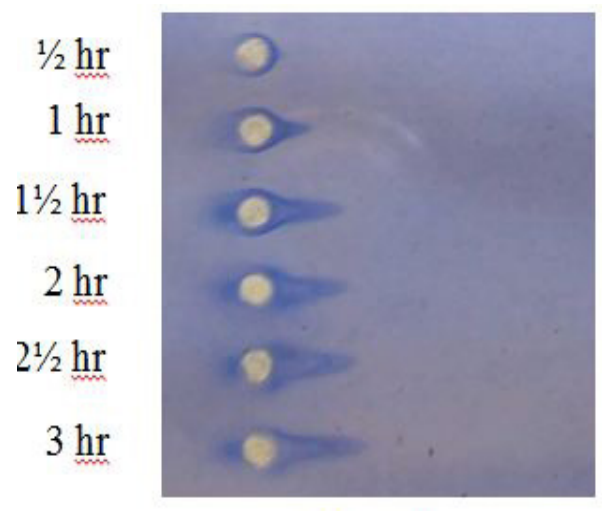

Gel buffer

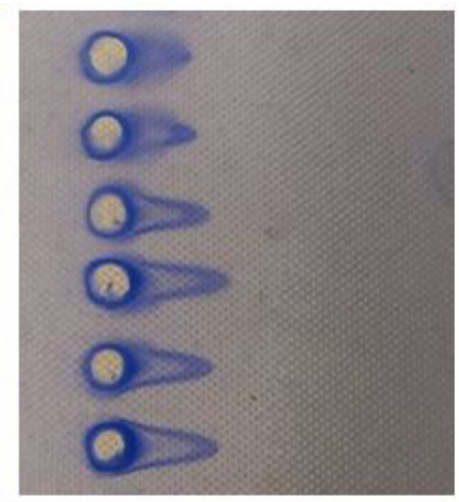

Ammonia

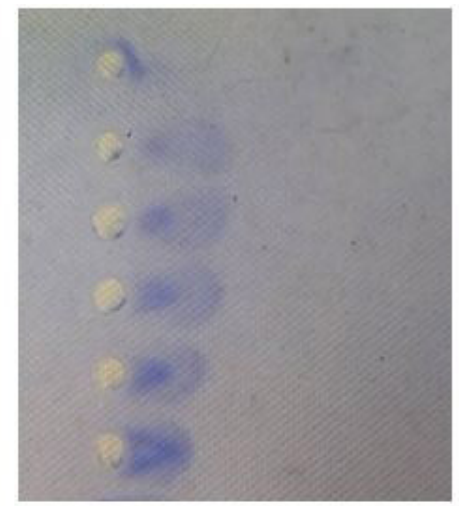

Saline

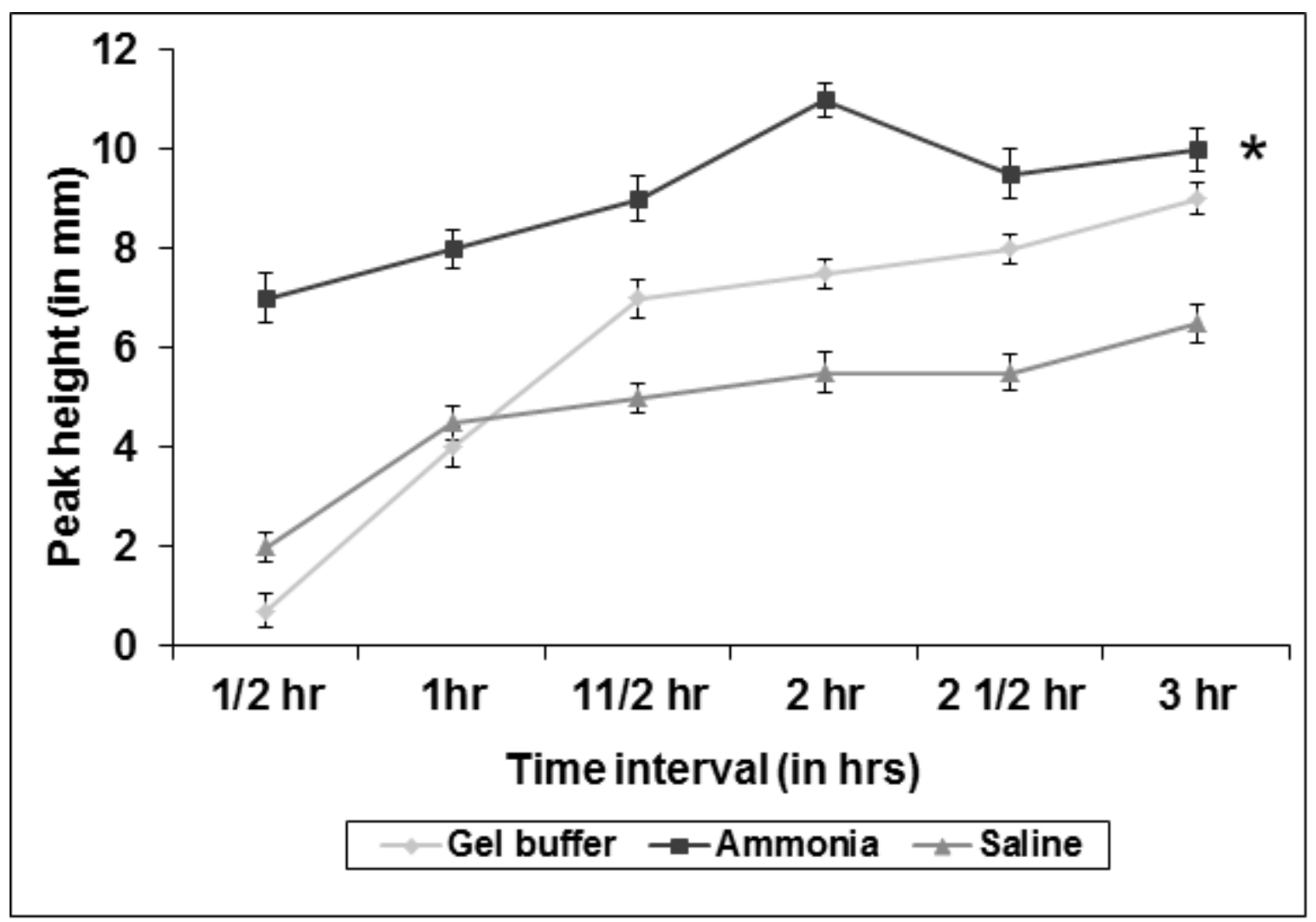

Figure 2f: Immunogram showing rocket- like precipitin peaks and a line graph demonstrating the extraction efficiency of protein extractants at different time intervals for item 6 . Results of line graph are means \pm SD $(n=3)$. Two-way ANOVA showed significant effect of stain extractants and time on extraction efficiency of proteins in rocket immunoelectrophoresis $\left({ }^{*} \mathrm{p}<0.05 ; 2\right.$-way ANOVA)

\section{Conclusion}

Immunological methods for human identification though have been completely supplanted by DNA technology in recent years, the techniques of CIE and RIE are still utilized for human origin determination during blood grouping analysis and interpretation of grouping results in forensic serology laboratories. The present study reports for the first time a qualitative and quantitative study employing CIE and RIE respectively on protein extractants employed for human origin determination of blood. CIE revealed sharp precipitin lines for all the items of stain extracts of ammonia collected at various intervals of time. In contrast, gel buffer and saline extracts of item 4 did not show any precipitin lines at any of the six half an hour samples. Similarly, rocket immunoelectrophoresis also demonstrated sharp precipitin peaks with greater peak heights being observed for ammonia at 2-3 hours of sample, compared to gel buffer and saline. The current study results therefore suggests that ammonia (5\%) solution could very well be used as a better protein extractant for rapid human origin determination of blood from stained materials of diverse types.

\section{Acknowledgement}

The authors wish to thank Mr.T. Janakiram, Deputy Director, Regional Forensic Science Laboratory, Madurai for the support and encouragement. 


\section{References}

1. Forensic Serology (2005) Laboratory Procedure Manual. Directorate of Forensic Science, New Delhi, India.

2. Anbalagan K (1999) An Introduction to Electrophoresis. Biotech-Yercaud, India: 141-4.

3. Bansal RP (1981) Quick diagnosis of rinderpest by detection of antigen by counter-immunoelectrophoresis. Ind J Anim Sci 53:139-42.

4. Laurell CB (1966) Quantitative estimation of proteins by electrophoresis in agarose gel containing antibodies. Anal Biochem 15: 45-52.

5. Bals B, Teachworth L, Dale B, Balan V (2007) Extraction of proteins from switchgrass using aqueous ammonia within an integrated biorefinery. Appl Biochem Biotechnol 143: 187-98.

6. Bussard A, Huet J (1959) Description of a technique which simultaneously combines electrophoresis and immunological precipitation in a gel. Biochim Biophys Acta 34: 258-260. 